\title{
Periodontal pathogens Porphyromonas gingivalis and Fusobacterium nucleatum promote tumor progression in an oral-specific chemical carcinogenesis model
}

\author{
Adi Binder Gallimidi ${ }^{1,2}$, Stuart Fischman², Brurya Revach ${ }^{1}$, Raanan Bulvik ${ }^{1}$, Alina \\ Maliutina2 ${ }^{2}$, Ariel M. Rubinstein ${ }^{1}$, Gabriel Nussbaum ${ }^{2, *}$, Michael Elkin ${ }^{1, *}$ \\ ${ }^{1}$ Sharett Oncology Institute, Hadassah-Hebrew University Medical Center, Jerusalem, Israel \\ ${ }^{2}$ Institute of Dental Sciences, Hebrew University-Hadassah Faculty of Dental Medicine, Jerusalem, Israel \\ *These authors have contributed equally to this work \\ Correspondence to: \\ Michael Elkin, e-mail: melkin@hadassah.org.il \\ Gabriel Nussbaum, e-mail: gabrieln@ekmd.huji.ac.il \\ Keywords: oral cancer, TLR2, STAT3, IL-6, periodontitis \\ Received: April 16, $2015 \quad$ Accepted: May 26, 2015 \\ Published: June 08, 2015
}

\section{ABSTRACT}

Oral squamous cell carcinoma (OSCC) is a lethal disease whose incidence is increasing. Epidemiologic studies demonstrate an association between periodontitis and oral cancer, and periodontal pathogens are implicated in the pathogenesis of numerous disorders, including rheumatoid arthritis, cardiovascular diseases, diabetes and gastrointestinal malignancies. Nevertheless, a causal role for periodontal pathogens in OSCC has not been shown, partly due to the lack of an appropriate animal model. Here, utilizing a newly-established murine model of periodontitisassociated oral tumorigenesis, we report that chronic bacterial infection promotes OSCC, and that augmented signaling along the IL-6-STAT3 axis underlies this effect. Our results indicate that periodontal pathogens $P$. gingivalis and $F$. nucleatum stimulate tumorigenesis via direct interaction with oral epithelial cells through Tolllike receptors. Furthermore, oral pathogens stimulate human OSCC proliferation and induce expression of key molecules implicated in tumorigenesis. To the best of our knowledge, these findings represent the first demonstration of a mechanistic role for oral bacteria in chemically induced OSCC tumorigenesis. These results are highly relevant for the design of effective prevention and treatment strategies for OSCC.

\section{INTRODUCTION}

Chronic infections are increasingly recognized as an important epidemiologic/environmental determinant in cancer development. Almost $20 \%$ of human malignancies can be linked to infectious agents [1]. Among infection-related neoplasms, cancers of the stomach, liver and the uterine cervix are best characterized and attributed to Helicobacter pylori, hepatitis $\mathrm{B}$ and $\mathrm{C}$ viruses, and human papilloma virus, respectively. In addition to the role in initiation of several tumor types, chronic infection is believed to contribute to cancer progression by activating tumor-promoting signaling pathways (e.g., NF-kB, STAT3), thereby augmenting production of antiapoptotic proteins, growth factors, and cytokines that foster cancer growth, dissemination and resistance to therapy [1-6].

Oral cavity squamous cell carcinoma (SCC) ranks among the top 10 most common cancers worldwide $[7,8]$.
The tongue is the most common anatomic site (up to 50\%) of oral cancer in the western world [9]. The oral cavity, [including the tongue $[10,11]$, is naturally inhabited by microbial communities that exist in a balanced immunoinflammatory state with the host. However, certain species, such as Porphyromonas gingivalis (P. gingivalis), can disrupt this equilibrium, resulting in a dysbiotic host-microbiota interaction $[6,12]$. Subsequently, other microbial species, such as Fusobacterium nucleatum (F. nucleatum), can become opportunistically pathogenic, and the combined effect of a dysbiotic microbial community along with a dysregulated immune response ultimately causes periodontal disease $[6,12]$, a chronic infectious/inflammatory condition that leads to soft tissue damage and eventually to bone resorption. Ironically, while involvement of these well-studied periodontal microorganisms in several types of gastrointestinal tract 
cancers (i.e., colon $[13,14]$, and pancreatic $[15,16]$ ) was recently demonstrated, a mechanistic link between these bacteria and oral cavity SCC is much less established (despite the wealth of epidemiological data suggesting such involvement [5, 7, 17-20]).

Importantly, bacterial pathogens are often present in oral tumors, and chronic immune cell infiltration is an accompanying histological feature of oral cavity SCC progression $[6,7,21,22]$. Nevertheless, a causal role of these pathogens in the etiology and progression of oral cavity SCC remains underappreciated [5], and further research is handicapped by the lack of an appropriate animal model.

Here we report the establishment of a new murine model of chronic infection-associated oral tumorigenesis, combining experimental mouse periodontitis [23] induced by $P$. gingivalis and $F$. nucleatum, along with administration of a specific oral carcinogen 4-nitroquinoline-1-oxide (4NQO) [24]. The choice of the bacteria was based on the fact that these pathogens are often present in the oral cavity and in tumor tissue $[6,7,21,22]$. Furthermore, co-infection with $P$. gingivalis and $F$. nucleatum induces greater inflammation and bone resorption as compared to infection with each organism alone [23]. Utilizing this experimental system we found that chronic $P$. gingivalis/ $F$. nucleatum infection profoundly affects oral cavity SCC progression and that augmented signaling along the IL-6-STAT3 axis may underlie this effect. Moreover, our results indicate that periodontal pathogens may stimulate tumorigenesis via direct interaction with cancerous and pre-cancerous oral epithelial cells, through activation of epithelial Toll-like receptors (TLR). Validating this mode of action in human oral cavity SCC cells in vitro, we detected that specific stimulators of TLR2/1 and TLR4 (which are expressed by SCC cells), or challenge with $P$. gingivalis and F. nucleatum, induce key molecular players mechanistically involved in oral tumor growth and aggressiveness (i.e., IL-6, cyclin D1, TNF $\alpha$, MMP9, heparanase) [2, 7, 21, 25-30]. Causal involvement of epithelial TLR signaling was further confirmed by applying TLR2 neutralizing antibody. Collectively, our findings provide experimental evidence that a periodontal pathogen-rich environment profoundly affects tumor progression in the oral cavity, conferring an aggressive phenotype to oral cavity SCC.

\section{RESULTS}

\section{Mouse model of periodontal infection-associated oral tumorigenesis}

To elucidate the role of chronic infection in oral cavity SCC pathogenesis, we established and characterized a new experimental system (Figure 1) that combines the mouse model of chronic periodontitis [23] with the carcinogen 4-nitroquinoline-1-oxide (4NQO)induced oral carcinoma model [24, 31]. Briefly, mice were administered $4 \mathrm{NQO}$ for 8 weeks, as described in $[24,32,33]$ and further detailed in Methods (Figure 1, grey arrow). A group of the 4NQO-treated mice were repeatedly infected with a mixture of two major human periodontal pathogens, $P$. gingivalis and $F$. nucleatum suspended in CMC, as described in Methods (Figure 1, dashed arrows). Infection with both bacteria is a reliable model of experimental periodontitis, known to induce a pronounced inflammatory response in the gingiva that leads to osteoclast activation and alveolar bone resoption [23]. The non-infected 4NQO-treated mice were administered $\mathrm{CMC}$ alone. Of note, both bacteria were recovered from the tongue surface following oral challenge by swabbing and culturing, and by PCR (Supplementary Figure 2A), and chronic challenge led to an infiltrate dominated by macrophages in the tongue subepithelium (Supplementary Figure 2B). Thus, in addition to aggregating within biofilms on the tooth surface and within the gingival crevice, in this experimental model $P$. gingivalis and $F$. nucleatum are present on the mouse tongue surface. These observations are in agreement with findings in human oral cavity, where periodontal bacteria are abundantly present on the tongue dorsum [11] with similar prevalence as in the subgingival biofilm $[10,34]$.

4NQO was administered for 8 weeks (as in [24, 32, 33]) and since we hypothesized that infection may enhance

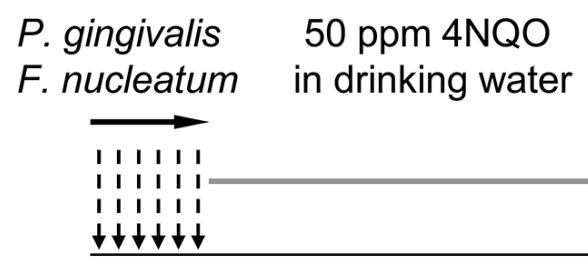

Experimental weeks: $0 \quad 2$

\section{P. gingivalis \\ F. nucleatum \\ Tissue collection and analysis}

$\begin{array}{lllllllllllllllll}1 & 1 & 1 & 1 & 1 & 1 & 1 & 1 & 1 & 1 & 1 & 1 & 1 & 1 & 1 & 1\end{array}$

$\begin{array}{lllllllllllllllll}1 & 1 & 1 & 1 & 1 & 1 & 1 & 1 & 1 & 1 & 1 & 1 & 1 & 1 & 1 & 1\end{array}$

I I I I I I I I I I I I I I I I I I I

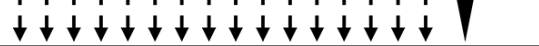

10
18

Figure 1: Schematic representation of the periodontal pathogen-associated oral tumorigenesis model. Mice were administered with oral carcinogen $4 \mathrm{NQO}(50 \mathrm{ppm})$ in the drinking water for 8 weeks (grey arrow). In some of the 4NQO-treated mice chronic periodontitis was induced by repeated oral infection with a mixture of $P$. gingivalis and $F$. nucleatum every other day, initiated 2 weeks prior to 4 NQO administration, and continued ( 2 times/week) until week 18 (black arrows). The non-infected mice were treated with vehicle alone. At the end of experimental week 18 mice were sacrificed (black arrowhead), their tongues harvested and processed for histological examination and immunostaining. 
tumorigenesis, the mice were sacrificed on week 18 (Figure 1), a relatively early time point compared to other studies [31]. Tongues were excised and serial H\&E stained sections were evaluated in a blinded fashion by an oral pathologist (S. F.). Tongue carcinoma was observed in 6 out of 7 infected mice and in 5 out of 7 non-infected mice. All carcinomas were graded as moderately differentiated except for one in the group infected with bacteria that was graded as poorly differentiated.

Morphometric and immunohistochemical analysis revealed that $P$. gingivalis/F. nucleatum chronic infection markedly enhanced the severity of the tongue tumors. Tumors from infected mice, in comparison to non-infected mice, were 2.5 times larger ( $p<0.05$, Figure $2 \mathrm{~A})$, and were significantly more invasive (Figure $2 \mathrm{~B}$ ). Furthermore, the expression of cyclin D1, a pivotal oncogene in experimental [25] and human [26] oral tumorigenesis, was significantly enhanced in infected vs. non-infected mice, both in cancerous and non-cancerous tongue epithelium (Figure 2C, 2D).

We next hypothesized that in infected mice the periodontal pathogens, rather than $4 \mathrm{NQO}$, may be mainly responsible for the upregulation of cyclin D1, acting via a STAT3 dependent-mechanism. Indeed, STAT3 is an important mediator of oral cavity SCC tumorigenesis in clinical and experimental settings [35-39]. STAT3 is one of the key signaling molecules which is responsible for induction of cyclin D1[40], although additional pathways (e.g. MAPK-ERK, Wnt) are known to regulate cyclin D1 as well. STAT3 also controls additional genes driving proliferation, suppression of apoptosis and aggressive tumor behavior [40]. Interestingly, the STAT3 pathway is reportedly activated in oral epithelial cells cultured in vitro in the presence of $P$. gingivalis $[41,42]$. To test this hypothesis, we analyzed the activation status of STAT3 in tongue epithelium of mice infected with periodontal pathogens but not exposed to 4NQO. Immunostaining for phosphoSTAT3 (pSTAT3) revealed that three consecutive administrations of $P$. gingivalis/ $F$. nucleatum sufficed to markedly induce STAT3 activation in the tongue epithelium, as evidenced by a more than 3 -fold increase $(p$ $=0.01)$ in the number of cells positive for nuclear-localized pSTAT3 in infected vs. non-infected mice (Figure 3). These findings are in agreement with the proposed role of STAT3 in fostering oral tumorigenesis [35-39], and may explain elevated levels of the STAT3 target gene cyclin D1 found in both cancerous and non-cancerous tongue epithelium of $P$. gingivalis/F. nucleatum infected mice (Figure 2C, 2D).

STAT3 activation is induced by several cytokines, most notably IL-6 [43]. We therefore studied the effect of $P$. gingivalis/F. nucleatum infection on IL-6 expression in mouse tongue tissue. As shown in Figure 4A, quantitative RT-PCR analysis revealed a 3 fold increase in IL-6 mRNA levels in tongues harvested from mice following repeated infection with $P$. gingivalis/F. nucleatum. Given the increase in macrophage infiltration found in the tongues of $P$. gingivalis/ F. nucleatum infected mice (Supplementary Figure 2B), and the known role of macrophages in IL- 6 production, it would be straightforward to assume that the observed increase in IL-6 expression (Figure 4A) occurs primarily in macrophages. However, double-immunofluorescent staining with antibodies directed against F4/80 and IL-6 failed to reveal co-localization of IL-6 with macrophages in the tongues of infected mice. Moreover, immunochemical analysis revealed that epithelial cells per se represent a key source of IL-6 in this experimental system (Figure 4B).

\section{In vitro effects of $P$. gingivalis and $F$. nucleatum on human oral cavity SCC cells}

The above findings, together with reports that epithelial cells of the oral cavity express TLRs [22, 44, 45], led us to speculate that $P$. gingivalis and $F$. nucleatum trigger TLR signaling in pre-cancerous/cancerous epithelium, resulting in overexpression of epithelial-derived IL-6. To validate the proposed mode of action, we co-incubated $P$. gingivalis $F$. nucleatum with tongue epithelium-derived oral cavity SCC cell lines SCC-25 and CAL 27. We first verified the expression and functionality of TLR2 and TLR4 in SCC-25 and CAL 27 cells by RT-PCR and by production of IL-6 in response to treatment with ligands specific for TLR2/1 (lipopeptide PAM3CSK4) or TLR4 (lipopolysaccharide, LPS) (Supplementary Figure 3). Moreover, as shown in figure 5, and in agreement with in vivo observations (Figure 4), exposure to each of the pathogens (or to a mixture of both) significantly increased the expression of IL-6 by SCC-25 (Figure 5A, empty bars) and CAL27 (Figure 5B, empty bars) cell lines. Importantly, TLR2 inhibition markedly inhibited pathogen-induced IL-6 expression (Figure 5, filled bars), whereas treatment with a TLR4 inhibitor did not interfere with pathogen-induced IL-6 expression, consistent with the dominant role of TLR2 in the innate response to $P$. gingivalis and $F$. nucleatum demonstrated by us and others [46-50].

The in vitro findings demonstrating involvement of TLR2 (Figure 5) are in agreement with the observation that in vivo infection with $P$. gingivalis/F. nucleatum induced NF-кB signaling (a known consequence of TLR activation [45]) in mouse tongue epithelium, as evidenced by a 3-fold increase in the percentage of epithelial cells positive for nuclear p65 in infected vs. non-infected mice 6 days post infection (24 $\pm 2.6 \%$ vs. $7 \% \pm 1.5, P<0.01)$. Of note, exposure of oral cavity SCC cells to the periodontal pathogens resulted in the induction of additional cytokines, enzymes and bioactive molecules implicated in oral cavity SCC proliferation, survival and aggressiveness (i.e., cyclin D1, TNF $\alpha$, MMP9, and heparanase [21, 25-30]) (Supplementary Figure 4).

Finally, co-incubation with either $P$. gingivalis, $F$. nucleatum or a mixture of both significantly stimulated in vitro proliferation of human oral cavity SCC cells (Figure 6), in further agreement with the augmented tumor growth observed under $P$. gingivalis/F. nucleatum infection in vivo (Figure 2). Moreover, inhibition of TLR2 with neutralizing antibody abrogated the effect of $P$. gingivalis/F. nucleatum on SCC-25 proliferation, supporting the role of TLR2 in the pro-tumorigenic effects of the pathogens (Figure 6). 

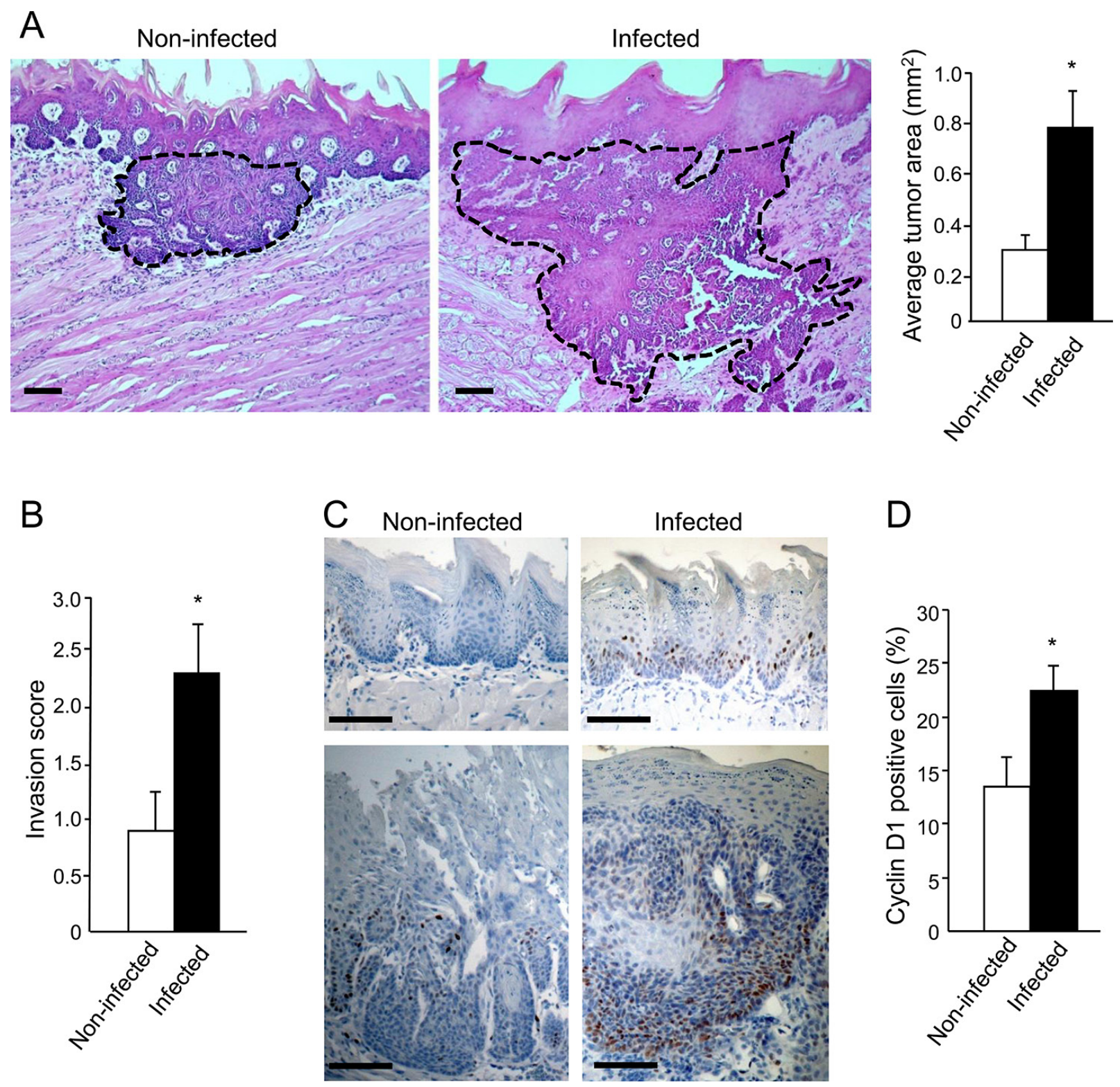

Figure 2: Increased tumor severity in $\boldsymbol{P}$. gingivalis/F. nucleatum infected mice. A, B. Serial tongue sections (5 $\mu \mathrm{m}$ thick) harvested from 4NQO-treated, non-infected and infected mice on week 18 were stained with H\&E and visualized with a Zeiss axioscope microscope. A. The area of each neoplastic lesion was determined with Axio Vision Image software. Left, middle. Representative microphotographs of H\&E stained tongue sections. Tumors are delineated by dashed lines; Scale bars: $200 \mu \mathrm{m}$. Right. Average tumor area in non-infected (empty bar) and infected (black bar) mice on experimental week 18. Data are the mean \pm SE, $n=5$ mice per condition; $* p=0.004$ (Mann-Whitney). B. Invasive score of the tumors found in non-infected (empty bar) and infected (black bar) mice was determined as described in Methods and in Supplementary Figure 1. Data are the mean \pm SE, $n=7$ mice per condition, ${ }^{*} p=0.029$ (Mann-Whitney). C, D. Immunostaining with anti cyclin D1 antibody reveals enhanced expression of cyclin D1 in non-cancerous (top) and cancerous (bottom) tongue epithelium of infected vs. non-infected mice. C. Representative images of cyclin D1 immunostained sections are shown; Scale bars: $100 \mu \mathrm{m}$. D. Percentage of Cyclin D1-immunostained cells in the epithelium was quantified as the number of positively stained cells per existing total epithelial cells, based on [58] in 5 randomly selected high-power microscopic fields per mouse at magnification $\times 200$. Data are the mean $\pm \mathrm{SE}, n=4$ mice per condition $* p=0.0026$ (Student's $t$-test).

Of note, oral cavity SCC cell proliferation was not affected by co-incubation with L. casei (commensal bacteria found in the human intestine and mouth, which is not implicated in carcinogenesis) (Figure 6), suggesting that the effects of periodontal pathogens in this setting cannot be generalized to all oral bacteria.

\section{DISCUSSION}

$P$. gingivalis and $F$. nucleatum, best known for their involvement in periodontitis, have been implicated in the pathogenesis of several chronic diseases, as well as various types of gastrointestinal malignancies 
A

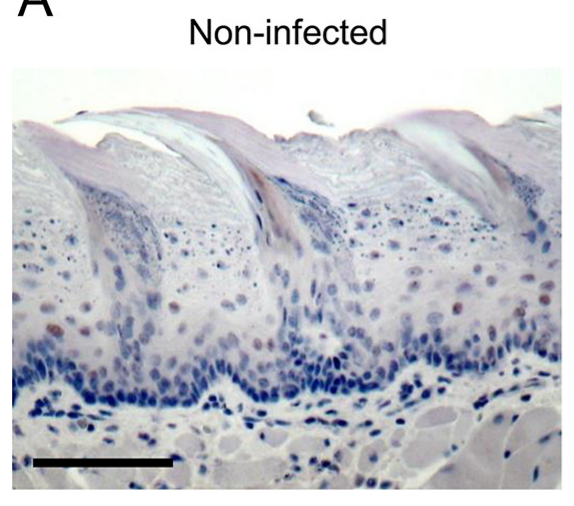

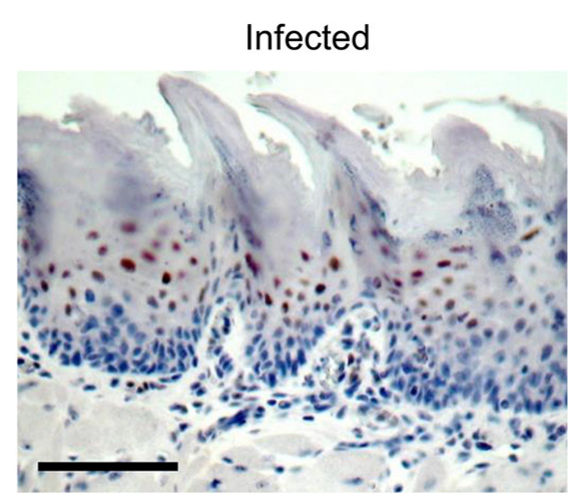

B

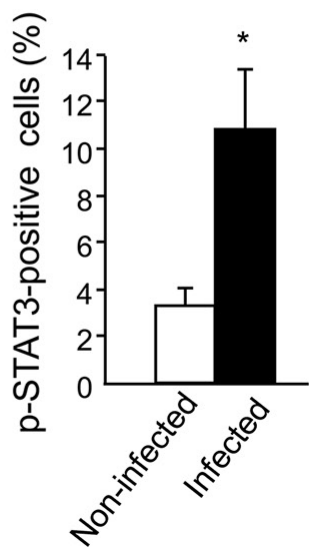

Figure 3: Increased STAT3 activation in tongue epithelium of infected mice. C57/B16 mice were infected with a mixture of $P$. gingivalis and F. nucleatum (as described in Methods) every other day for 6 days. Mice were sacrificed twenty-four hours after the last infection, their tongues removed and processed for immunostaining with anti-pSTAT3 antibody. A. Immunostaining with anti pSTAT3 antibody reveals increased levels of nuclear-localized pSTAT3 in tongue epithelium of infected (right) vs. non-infected (left) mice. Representative images of are shown. Magnification $\times 200$ B. Percentage of pSTAT3-immunostained cells in the epithelium was calculated in $\geq 5$ microscopic fields per mouse. Data are the mean $\pm \mathrm{SE},{ }^{*} p=0.01$ (Student's $t$-test). Scale bars: $100 \mu \mathrm{m}$.

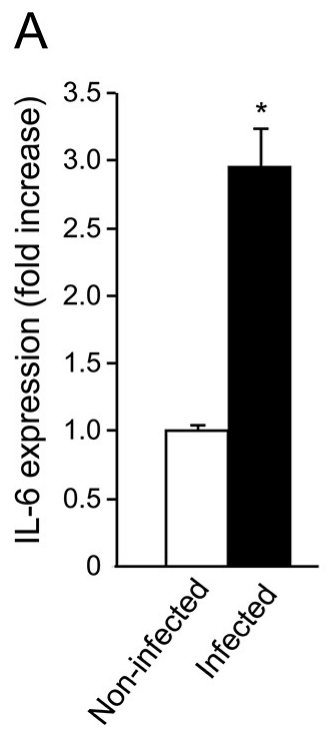

B

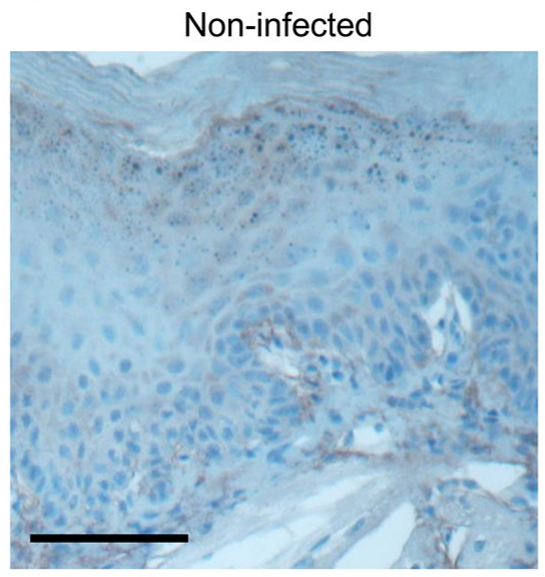

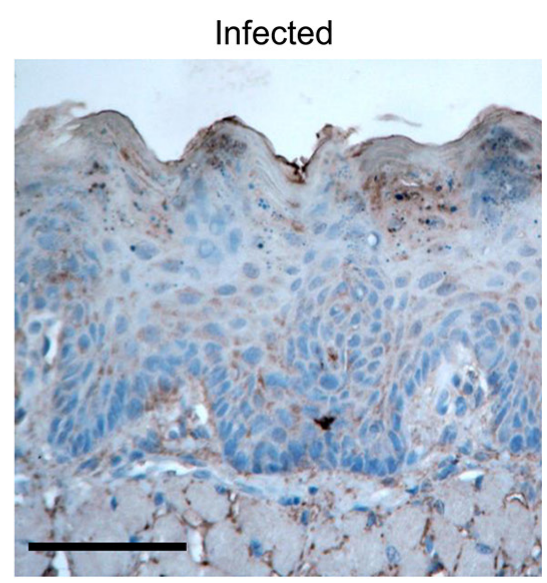

Figure 4: Increased IL-6 levels in tongue epithelium of infected mice. A. Mice non-infected (white bar) or infected (black bar) with a mixture of $P$. gingivalis and $F$. nucleatum every other day for 6 days (as described in Methods) were sacrificed four hours after the last infection. The tongue mucosa was isolated and processed for RNA. Quantitative RT-PCR analysis revealed a 3 fold increase in IL-6 mRNA levels in the tongue mucosa of infected mice. Data are the mean $\pm \mathrm{SE},{ }^{*} p=0.014$ (Student's $t$-test). B. Immuno-histochemical analysis with anti-IL-6 antibody revealed expression of IL-6 protein in epithelial compartment of the tongue tissues harvested non-infected and infected mice treated with 4NQO as described in Methods and in Figure 1. Scale bars: $100 \mu \mathrm{m}$.

(e.g. colorectal, pancreatic) [13-16]. Paradoxically, an involvement of these oral pathogens in the etiology and progression of oral cavity SCC is much less established, despite the wealth of epidemiological data suggesting such involvement $[5,6,19]$. To address the paucity of mechanistic approaches for testing the effects of periodontal bacteria in oral cavity SCC, we established an animal model of chronic $\mathrm{P}$. gingivalis/F. nucleatum infection-associated oral tumorigenesis. Here we demonstrate that $P$. gingivalis/F. nucleatum chronic infection promotes the growth and severity of 4NQOinduced tongue tumors (Figure 2); we further show that augmented signaling along the IL-6-STAT3 axis likely underlies this effect (Figures 3-5).

Similar to other anatomic sites, chronic infection in the oral cavity is likely to contribute to tumorigenesis 
A

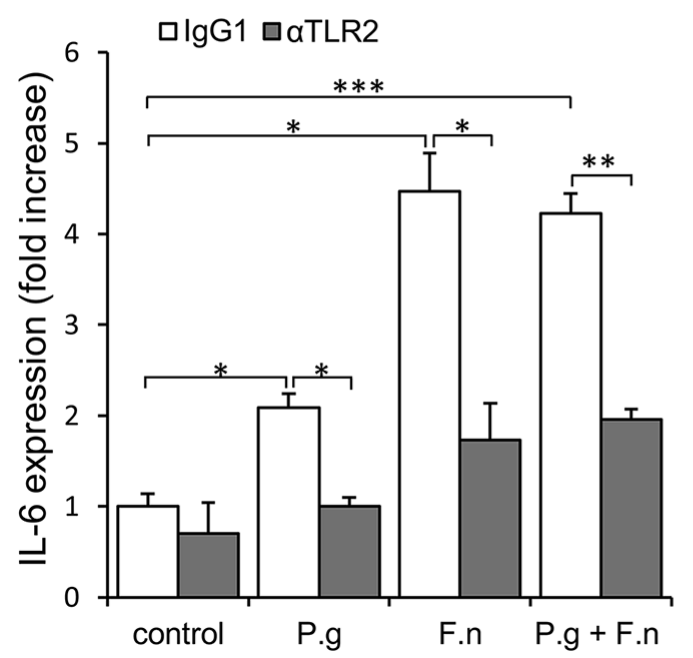

B

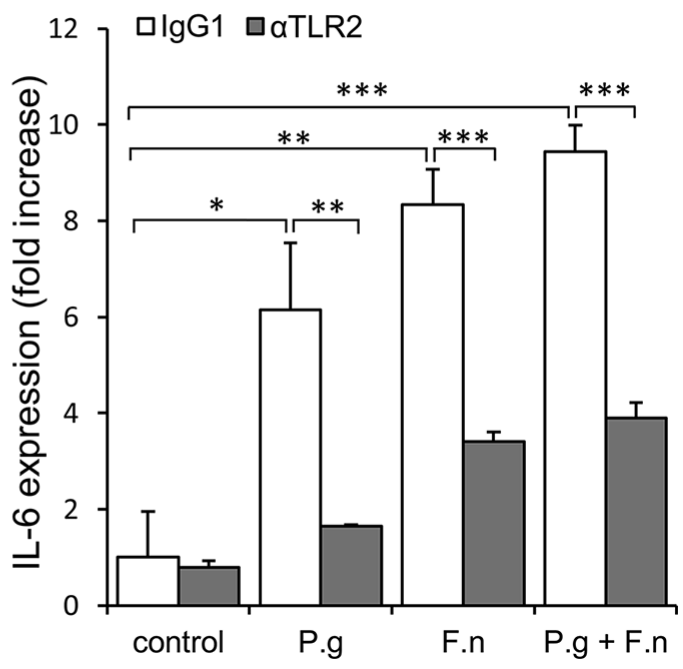

Figure 5: Increased expression of IL-6 in oral cavity SCC cell lines following co-culture with P. gingivalis and F. nucleatum. SCC-25 A. and CAL 27 B. cells were cultured alone (control) or with P. gingivalis (P.g), F. nucleatum (F.n), or mixture of P. gingivalis and F. nucleatum (P.g + F.n), as described in Methods. In some plates neutralizing antibody directed against TLR2 ( $\alpha$ TLR2) was added to SCC-25 (A, filled bars) and CAL 27 (B, filled bars) cells, cultured alone (control) or with P.g, F.n, or mixture of P.g + F.n as described in Methods. Empty bars: isotype control (IgG1). Quantitative RT-PCR was used to assess expression of IL-6. Data are the mean $\pm \mathrm{SE} ; * p<0.05,{ }^{* *} p<0.01, * * * p<0.001$.

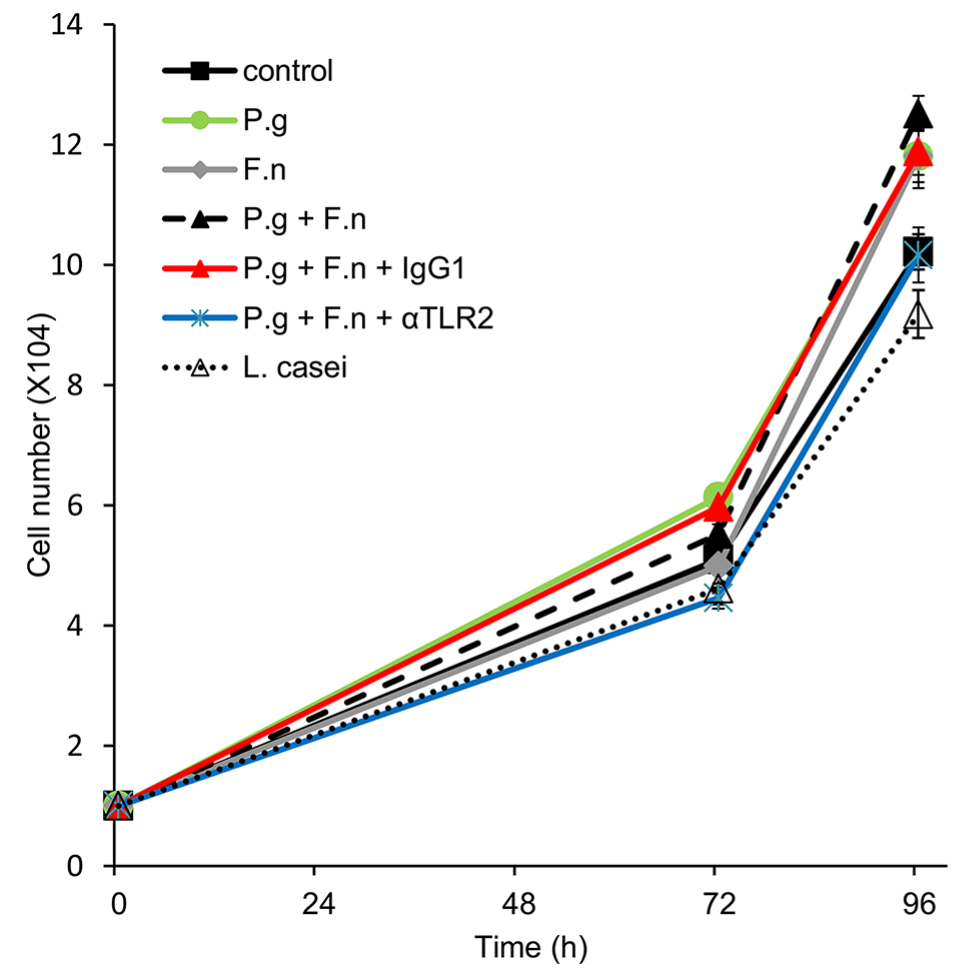

\begin{tabular}{|l|c|}
\hline \multicolumn{1}{|c|}{ Conditions } & $\begin{array}{c}\text { P values } \\
\text { (96h) }\end{array}$ \\
\hline control vs. P.g + F.n & $>0.001$ \\
\hline control vs. P.g & $>0.01$ \\
\hline control vs. F.n & $>0.01$ \\
\hline $\begin{array}{l}\text { P.g + F.n + IgG1 vs. } \\
\text { P.g + F.n + } \alpha \text { TLR2 }\end{array}$ & $>0.01$ \\
\hline control vs. L.casei & \multicolumn{1}{|c|}{ ns } \\
\hline
\end{tabular}

Figure 6: $\boldsymbol{P}$. gingivalis and $\boldsymbol{F}$. nucleatum stimulate in vitro proliferation of human SCC cells. SCC- 25 cells were plated on 24-well plates at $10^{4}$ cells per well (in quadruplicates) and cultured either alone (control) or in the presence of $P$. gingivalis (P.g), F. nucleatum (F.n), mixture of both (P.g + F.n), or L. Casei, as described in Methods. In some plates $\alpha$ TLR2 or the isotype control (IgG1) was added one hour prior to mixture of P.g + F.n. Cell numbers were determined as described in Methods. Data are the mean \pm SE. Inset: $p$ values determined by Student's $t$-test.

by several mechanisms, including aberrant activation of infiltrating immune cells, induction of DNA damage through generation of reactive oxygen and nitrogen species and increased levels of immunocyte-derived bioactive molecules that facilitate tumor progression $[7,43]$. In addition to these mechanisms, driven mainly 
by activated immunocytes, the novelty of our findings lies in the demonstration that periodontal pathogens directly stimulate cancerous cells of epithelial origin, resulting in induction of SCC-promoting factors (Figure 5 and Supplementary Figure 4) and augmented cell growth (Figure 6). Moreover, applying a neutralizing antibody approach, we show an important role for epithelial-expressed TLR2 in this process. These findings are consistent with the recently demonstrated role of epithelial TLR2 in the progression of non-oral carcinomas (i.e. intestinal and breast) [51]. Indeed, due to the pivotal role of TLRs in immune responses, the majority of studies aimed at understanding TLR biology have focused on immunocytes, rather than on tumor cells. However, TLRs appear to be expressed by tumor cells as well $[44,45,52]$, including those originating from the normal oral mucosa and oral cancer (Ref. [22] and present study). These and other reports $[15,46,47,53]$, together with our findings that oral cavity SCC cells respond to $P$. gingivalis/F. nucleatum in a TLR2-dependent manner, (Figures. 5, 6, and Supplementry Figures 3,4), strengthen the notion that triggering of epithelial TLRs facilitates tumorigenesis in the oral cavity, although the involvement of additional receptors/pathways cannot be excluded [54]. Consistent with the TLR involvement, infection with $P$. gingivalis/F. nucleatum in vivo induced NF$\kappa \mathrm{B}$ signaling in mouse tongue epithelium, manifested by a higher number of epithelial cells positive for nuclear p65 NF- $\mathrm{BB}$ in infected vs. non-infected mice (24\% vs. $7 \%, P<0.01)$. Moreover, in vitro induction of epithelial IL-6 and TNF $\alpha$ (well-known TLR-


periodontal pathogens (Figure 5 and Supplementry Figure 4, left), is also in agreement with activation of a TLR-2-NF- $\kappa \mathrm{B}$ signaling pathway. Thus, in the evolving story of microbial/mucosal/immune interplay in the pathogenesis of oral cavity SCC, our study adds a new level of complexity, highlighting the role of a direct interaction between pathogens and epithelial cells. Collectively, our results suggest that exposure of oral epithelial cells to $P$. gingivalis $/ F$. nucleatum triggers TLR signaling, resulting in IL-6 production that activates STAT3 which in turn induces important effectors driving oral cavity SCC growth and invasiveness (i.e., cyclin D1, MMP9, heparanase). Although further studies are warranted to fully unravel the intricate network of molecular and cellular events underlying the action of periodontal pathogens in oral cavity SCC tumorigenesis (including the contribution of extracellular bacteria and their products vs. intracellular bacteria), our present findings underscore the importance of epithelial-bacterial interactions in this complex network. Our model may offer new approaches not only to the further understanding of this connection, but also to the design of novel prevention/treatment strategies for oral cavity SCC in the setting of chronic oral infection.

\section{MATERIALS AND METHODS}

\section{In vivo carcinogenesis model}

Ten- to twelve-week-old Balb/c male mice were obtained from Harlan Laboratories (Jerusalem, Israel), housed at 2-5 per cage, provided with water and regular chow diet ad libitum, and maintained in a 12-h/12-h light/ dark cycle. Mice were randomly divided into two groups ( $n=7$ mice per group) and administered $50 \mathrm{ppm}$ 4NQO for 8 weeks in their drinking water. One group was repeatedly infected with a mixture of $P$. gingivalis (strain 381) and F. nucleatum (strain PK1594) $\left(300 \mu \mathrm{l}\right.$ of $10^{10}$ bacteria/ $\mathrm{ml}$ and $100 \mu \mathrm{l}$ of $10^{9} \mathrm{bacteria} / \mathrm{ml}$ respectively) suspended in $2 \%$ carboxymethylcellulose (CMC), as described previously [23]. Mice in this group were orally infected 3 times per week starting two weeks prior to 4NQO administration. Infection was repeated at 2 times per week for 8 weeks after 4NQO withdrawal, as shown in Figure 1. During the period of $4 \mathrm{NQO}$ administration mice were not infected with the bacteria mixture (4NQO has been previously reported to exert anti-bacterial action [56]). The second group was treated with vehicle (CMC) alone. All mice were sacrificed on week 18, and their tongues were harvested and processed for histological examination and immunostaining. Animal experiments were approved by the Institutional Animal Care and use Committee.

\section{Tumor histopathology and immunostaining}

Tongues were fixed in 4\% paraformaldehyde, embedded in paraffin, and thin-sectioned $(5 \mu \mathrm{m})$. Every 20th section of the tissues was stained with H\&E and visualized with a Zeiss axioscope microscope. Neoplastic lesions were scored in a blinded fashion by an expert oral pathologist (S.F.). The size of each neoplastic lesion was determined with Zeiss Image software (AxioVision) as previously described [57].

Tumor invasion was graded from 0 to 3 as follows (Supplementary Figure 1): 0 = no evidence of invasion, $1=$ malignant cells deep to basal cell layer, no invasion into striated muscle; $2=$ minor invasion into striated muscle; 3 = invasion through the full depth of striated muscle. For each mouse, the entire tongue was reviewed and all tumors were graded. Seven mice per experimental condition were analyzed, and the highest score obtained for each mouse was used to calculate the invasiveness index. Immunostaining of the paraffin-embedded sections was performed as previously [57]. Primary antibodies used were anti-cyclin D1 (1:50, Thermo SCIENTIFIC, \#RM9104-S0), anti-p-STAT3 (1:100, Cell Signaling, D3a7), anti-NF-кB p65 (1:400, Cell signaling, D14E12), anti-F4/80 (1:400, Serotec, MCA497GA) and anti-IL-6 (1:400, Abcam, ab6672). Color was developed using the DAB substrate kit (Thermo Scientific). F4/80 positive cells were quantified as cells per mm epithelial length, including all epithelial layers and stroma above 
the muscle layer, as described [58]. Nuclear p-STAT3, cyclin D1 and p65 NF-kB -positive cells were quantified as the number of positively stained cells per existing total epithelial cells [58].

\section{Bacterial and eukaryotic cell culture}

$P$. gingivalis and $F$. nucleatum were grown in Wilkins media (Oxoid, Basingstoke, UK) for 2 or 1 days respectively, under anaerobic conditions at $37^{\circ} \mathrm{C}$. Lactobacillus casei (L. casei) was grown in M.R.S broth media (Oxoid, Basingstoke, UK) for 1 day under aerobic conditions at $37^{\circ} \mathrm{C}$. The bacteria were washed 3 times with sterile phosphate-buffered saline (PBS) before use. SCC25 and CAL 27 human tongue SCC cell lines, originally obtained from ATCC, were generously provided by Dr. I. Vlodavsky (Technion, Haifa, Israel). CAL-27 cell line was isolated from the lesion taken prior to treatment from a 56 year old male [59]; SCC-25 line was isolated from a tongue of 70 year old male [60]. Both lines are extensively characterized, widely used in oral cavity SCC studies [61], HPV-negative, have relatively long doubling times $(35 \mathrm{~h})$ and are non-invasive in vivo, as proven by the xenograft models $[60,62]$. Cells (tested negative for mycoplasma) were grown in DMEM supplemented with 1 $\mathrm{mM}$ glutamine, $50 \mu \mathrm{g} / \mathrm{ml}$ streptomycin, $50 \mathrm{U} / \mathrm{ml}$ penicillin, and $10 \%$ fetal calf serum (Biological Industries, Israel) at $37^{\circ} \mathrm{C}$ and $8 \% \mathrm{CO} 2$.

\section{In vivo infection with $P$. gingivalis and F. nucleatum}

Male Balb/c mice were orally infected every other day for 6 days with a mixture of $P$. gingivalis and F. nucleatum (300 $\mu \mathrm{l}$ of $10^{10}$ bacteria/ml and $100 \mu \mathrm{l}$ of $10^{9} \mathrm{bacteria} / \mathrm{ml}$ respectively). Mouse tongues harvested at the time points specified in the text were processed for immunostaining or snap-frozen for RNA isolation. Three mice per condition/time point were analyzed.

\section{Cell co-culture with bacteria and RNA isolation}

SCC-25 and CAL 27 were plated in 12-well plates at $2 \times 10^{5}$ cells per well in growth medium overnight. The cell confluence at the time of infection was $\leq 80 \%$. One hour prior to bacterial infection medium was changed to DMEM without streptomycin and penicillin and cells were incubated with $P$. gingivalis (MOI 100), F. nucleatum (MOI 5), a mixture of both, or left untreated. Specific anti-TLR2 neutralizing antibody (20 microg/ml, clone T2.5, eBioscience, Inc) or isotype control (clone MOPC 21) was added to some plates (as indicated in the text) one hour prior to addition of bacteria. Following 4 or 24 hours of incubation, cells were lysed and processed for RNA isolation using TRIzol (Invitrogen), according to the manufacturer's instructions.

\section{Analysis of gene expression by qRT-PCR}

Total RNA was isolated from snap-frozen tissue samples or cultured cells using TRIzol (Invitrogen), according to the manufacturer's instructions, and quantified by spectrophotometry. After oligo (dT)primed reverse transcription of $1 \mu \mathrm{g}$ total RNA, the resulting single stranded cDNA was amplified using the primers listed below. Real-time quantitative PCR (qRT-PCR) analysis was performed with an automated rotor gene system RG-3000A (Corbett research, Sydney, Australia). The PCR reaction mix (20 $\mu$ l) was composed of $10 \mu \mathrm{l}$ QPCR sybr master mix (Finnzymes, Espoo, Finland), $5 \mu$ of diluted cDNA (each sample in triplicate) and a final concentration of $0.3 \mu \mathrm{M}$ of each primer. Hypoxanthine guanine phosphoribosyl transferase (HPRT) primers designed in the lab using Primer-BLAST software (NCBI) were used as an internal control [63]. The following primers were utilized:

Human HPRT F: 5'-GCTATAAATTCTTTGCTGA CCTGC-3'， R: 5'-ATTACTTTTATGTCCCCTGTTG ACTG-3'.

Human IL-6 F: 5'-GGCACTGGCCAGAAAAC AACC-3',

R: 5'-GCAAGTCTCCTCATTGAATCC-3'. Human MMP9 F: 5'-CCTGGAGACCTGAGAACC AATC-3',

R: 5'-CCACCCGAGTGTAACCATAGC-3'. Human TNF $\alpha$ F: 5-CTGCCCCAATCCCTTTATT-3', R: 5'-CCCAATTCTCTTTTTGAGCC-3'.

Human Cyclin D1 F: 5'-TGTTCGTGGCCTCTAA GATGAAG-3',

R: 5'-AGGTTCCACTTGAGCTTGTTCAC-3'. Human heparanase F: 5'-CCAGCACGGAAATGAA AGA-3',

R: 5'-TCGATGGTGATGGACAGGAA-3'.

\section{Cell proliferation assay}

Cells were plated in 24-well plates at $10^{4}$ cells per well in the growth medium. One hour prior to bacterial infection medium was changed to DMEM without streptomycin and penicillin and cells were incubated with P. gingivalis (MOI 10), F. nucleatum (MOI 1), a mixture of both P. gingivalis and F. nucleatum, L. Casei (MOI 10), or left untreated. Cell numbers were counted at indicated time points using a hemocytometer. Each experiment was performed in quadruplicates and repeated at least twice. 


\section{Recovery of $P$. gingivalis and $F$. nucleatum from mouse tongues}

A sterile cotton swab was rubbed against the tongue surface of infected and non-infected mice, 4 hours after infection for 20 seconds and then vortexed in $100 \mu$ of prereduced transport media (Yeast Extract $5 \mathrm{~g} / \mathrm{L}$, Proteose Peptone $1 \mathrm{~g} / \mathrm{L}$, Cysteine- $\mathrm{HCl} 0.5 \mathrm{~g} / \mathrm{L}$, $\mathrm{NaCl} 8.58 .5 \mathrm{~g} / \mathrm{L}, \mathrm{Na} 2 \mathrm{HPO} 40.868 \mathrm{~g} / \mathrm{L}, \mathrm{KH} 2 \mathrm{PO} 4$ $0.528 \mathrm{~g} / \mathrm{L}, 0.1 \%$ Tween-80, 15\% Glycerol, $\mathrm{pH}=7$ ). An aliquot, plated onto supplemented blood agar, was incubated anaerobically for 2 weeks. P. gingivalis and $F$. nucleatum colonies were identified by their black pigmentation and yellow-gray color (respectively) and by PCR with primers specific for $P$. gingivalis $16 \mathrm{~S}$ rRNA and $F$. nucleatum. PCR conditions were as follows: an initial denaturation step at $95^{\circ} \mathrm{C}$ for 10 minutes, 30 cycles of denaturation at $94^{\circ} \mathrm{C}$ for 15 seconds, hybridization at $61^{\circ} \mathrm{C}$ for 30 seconds, and elongation at $72^{\circ} \mathrm{C}$ for 30 seconds. Primers used were:

P. gingivalis $16 \mathrm{~S}$ rRNA F: 5'-CTTGACTTCAG TGGCGGCAG-3'

R: 5'-AGGGAAGACGGTTTTCACCA-3'

$F$. nucleatum $\mathrm{F}$ : 5'-CAACCATTACTTTAACTC TACCATGTTCA-3'

R: 5'-ATTGACTTTACTGAGGGAGATTATGTAA AAATC-3'.

\section{Statistics}

Statistical differences were analyzed by the unpaired Student's $t$ test or the Mann-Whitney test. $P$ values $<0.05$ were considered statistically significant. All statistical tests were two-sided.

\section{CONFLICTS OF INTEREST}

The authors declare that they have no conflicts of interest.

\section{GRANT SUPPORT}

This work was supported by grants from the Israel Science Foundation (grant 806/14) and the Israel Cancer Association (to ME) and from the Israel Cancer Research Fund (to GN).

\section{REFERENCES}

1. Coussens LM, Zitvogel L, Palucka AK. Neutralizing tumorpromoting chronic inflammation: a magic bullet? Science. 2013; 339:286-291.

2. Hanahan D, Weinberg RA. Hallmarks of cancer: the next generation. Cell. 2011; 144:646-674.
3. Lax AJ, Thomas W. How bacteria could cause cancer: one step at a time. Trends Microbiol. 2002; 10:293-299.

4. Oikonomopoulou K, Brinc D, Kyriacou K, Diamandis EP. Infection and cancer: revaluation of the hygiene hypothesis. Clin Cancer Res. 2013; 19:2834-2841.

5. Atanasova KR, Yilmaz O. Looking in the Porphyromonas gingivalis cabinet of curiosities: the microbium, the host and cancer association. Mol Oral Microbiol. 2014; 29:55-66.

6. Whitmore SE, Lamont RJ. Oral bacteria and cancer. PLoS Pathog. 2014; 10:e1003933.

7. Hooper SJ, Wilson MJ, Crean SJ. Exploring the link between microorganisms and oral cancer: a systematic review of the literature. Head Neck. 2009; 31:1228-1239.

8. Chaturvedi AK, Engels EA, Anderson WF, Gillison ML. Incidence trends for human papillomavirus-related and -unrelated oral squamous cell carcinomas in the United States. J Clin Oncol. 2008; 26:612-619.

9. Warnakulasuriya S. Global epidemiology of oral and oropharyngeal cancer. Oral Oncol. 2009; 45(4-5):309-316.

10. Do Nascimento C, Sato S, Mardegan Issa JP, Edson Santos Barbosa R, Ferreira De Albuquerque Junior R. DNA Checkerboard method for bacterial detection of microbiota from teeth and tongue biofilms. A preliminary study. Minerva Stomatol. 2008; 57:561-567.

11. Faveri M, Feres M, Shibli JA, Hayacibara RF, Hayacibara MM, de Figueiredo LC. Microbiota of the dorsum of the tongue after plaque accumulation: an experimental study in humans. J Periodontol. 2006; 77:1539-1546.

12. Hajishengallis G, Lamont RJ. Beyond the red complex and into more complexity: the polymicrobial synergy and dysbiosis (PSD) model of periodontal disease etiology. Molecular Oral Microbiology. 2012; 27:409-419.

13. Kostic AD, Chun E, Robertson L, Glickman JN, Gallini CA, Michaud M, Clancy TE, Chung DC, Lochhead P, Hold GL, El-Omar EM, Brenner D, Fuchs CS, Meyerson M, Garrett WS. Fusobacterium nucleatum potentiates intestinal tumorigenesis and modulates the tumor-immune microenvironment. Cell Host Microbe. 2013; 14:207-215.

14. Rubinstein MR, Wang X, Liu W, Hao Y, Cai G, Han YW. Fusobacterium nucleatum promotes colorectal carcinogenesis by modulating E-cadherin/beta-catenin signaling via its FadA adhesin. Cell Host Microbe. 2013; 14:195-206.

15. Michaud DS. Role of bacterial infections in pancreatic cancer. Carcinogenesis. 2013; 34:2193-2197.

16. Michaud DS, Izard J, Wilhelm-Benartzi CS, You DH, Grote VA, Tjonneland A, Dahm CC, Overvad K, Jenab M, Fedirko V, Boutron-Ruault MC, Clavel-Chapelon F, Racine A, Kaaks R, Boeing H, Foerster J, et al. Plasma antibodies to oral bacteria and risk of pancreatic cancer in a large European prospective cohort study. Gut. 2013; 62:1764-1770.

17. Ahn J, Segers S, Hayes RB. Periodontal Disease, Porphyromonas Gingivalis (P. gingivalis) Serum Antibody 
Levels and Orodigestive Cancer Mortality. Carcinogenesis. 2012; 33:1055-1058.

18. Tezal M, Sullivan MA, Hyland A, Marshall JR, Stoler D, Reid ME, Loree TR, Rigual NR, Merzianu M, Hauck L, Lillis C, Wactawski-Wende J, Scannapieco FA. Chronic periodontitis and the incidence of head and neck squamous cell carcinoma. Cancer Epidemiol Biomarkers Prev. 2009; 18:2406-2412.

19. Ahn J, Chen CY, Hayes RB. Oral microbiome and oral and gastrointestinal cancer risk. Cancer Causes Control. 2012; 23:399-404.

20. Han YW, Houcken W, Loos BG, Schenkein HA, Tezal M. Periodontal disease, atherosclerosis, adverse pregnancy outcomes, and head-and-neck cancer. Adv Dent Res. 2014; 26:47-55.

21. Hohberger L, Wuertz BR, Xie H, Griffin T, Ondrey F. TNFalpha drives matrix metalloproteinase- 9 in squamous oral carcinogenesis. Laryngoscope. 2008; 118:1395-1399.

22. Szczepanski MJ, Czystowska M, Szajnik M, Harasymczuk M, Boyiadzis M, Kruk-Zagajewska A, Szyfter W, Zeromski J, Whiteside TL. Triggering of Toll-like receptor 4 expressed on human head and neck squamous cell carcinoma promotes tumor development and protects the tumor from immune attack. Cancer Res. 2009; 69:3105-3113.

23. Polak D, Wilensky A, Shapira L, Halabi A, Goldstein D, Weiss EI, Houri-Haddad Y. Mouse model of experimental periodontitis induced by Porphyromonas gingivalis/ Fusobacterium nucleatum infection: bone loss and host response. J Clin Periodontol. 2009; 36:406-410.

24. Wilkey JF, Buchberger G, Saucier K, Patel SM, Eisenberg E, Nakagawa H, Michaylira CZ, Rustgi AK, Mallya SM. Cyclin D1 overexpression increases susceptibility to 4-nitroquinoline-1-oxide-induced dysplasia and neoplasia in murine squamous oral epithelium. Mol Carcinog. 2009; 48:853-861.

25. Goessel G, Quante M, Hahn WC, Harada H, Heeg S, Suliman Y, Doebele M, von Werder A, Fulda C, Nakagawa H, Rustgi AK, Blum HE, Opitz OG. Creating oral squamous cancer cells: a cellular model of oralesophageal carcinogenesis. Proc Natl Acad Sci U S A. 2005; 102:15599-15604.

26. Bartkova J, Lukas J, Muller H, Strauss M, Gusterson B, Bartek J. Abnormal patterns of D-type cyclin expression and G1 regulation in human head and neck cancer. Cancer Res. 1995; 55:949-956.

27. Jackson-Bernitsas DG, Ichikawa H, Takada Y, Myers JN, Lin XL, Darnay BG, Chaturvedi MM, Aggarwal BB. Evidence that TNF-TNFR1-TRADD-TRAF2-RIP-TAK1IKK pathway mediates constitutive NF-kappaB activation and proliferation in human head and neck squamous cell carcinoma. Oncogene. 2007; 26:1385-1397.

28. Nagler R, Ben-Izhak O, Cohen-Kaplan V, Shafat I, Vlodavsky I, Akrish S, Ilan N. Heparanase up-regulation in tongue cancer: tissue and saliva analysis. Cancer. 2007; 110:2732-2739.
29. Leiser Y, Abu-El-Naaj I, Sabo E, Akrish S, Ilan N, BenIzhak O, Peled M, Vlodavsky I. Prognostic value of heparanase expression and cellular localization in oral cancer. Head Neck. 2011; 33: 871-877.

30. Sun L, Diamond ME, Ottaviano AJ, Joseph MJ, Ananthanarayan V, Munshi HG. Transforming growth factor-beta 1 promotes matrix metalloproteinase-9-mediated oral cancer invasion through snail expression. Mol Cancer Res. 2008; 6:10-20.

31. Hawkins BL, Heniford BW, Ackermann DM, Leonberger M, Martinez SA, Hendler FJ. 4NQO carcinogenesis: a mouse model of oral cavity squamous cell carcinoma. Head Neck. 1994; 16:424-432.

32. Park JW, Pitot HC, Strati K, Spardy N, Duensing S, Grompe M, Lambert PF. Deficiencies in the Fanconi Anemia DNA Damage Response Pathway Increase Sensitivity to HPV-Associated Head and Neck Cancer. Cancer Research. 2010; 70:9959-9968.

33. Tang XH, Knudsen B, Bemis D, Tickoo S, Gudas LJ. Oral cavity and esophageal carcinogenesis modeled in carcinogen-treated mice. Clin Cancer Res. 2004; 10:301-313.

34. Tanner AC, Paster BJ, Lu SC, Kanasi E, Kent R Jr., Van Dyke T, Sonis ST. Subgingival and tongue microbiota during early periodontitis. J Dent Res. 2006; 85:318-323.

35. Sriuranpong V, Park JI, Amornphimoltham P, Patel V, Nelkin BD, Gutkind JS. Epidermal growth factor receptorindependent constitutive activation of STAT3 in head and neck squamous cell carcinoma is mediated by the autocrine/ paracrine stimulation of the interleukin 6/gp130 cytokine system. Cancer Res. 2003; 63:2948-2956.

36. Squarize CH, Castilho RM, Sriuranpong V, Pinto DS Jr., Gutkind JS. Molecular cross-talk between the NFkappaB and STAT3 signaling pathways in head and neck squamous cell carcinoma. Neoplasia. 2006; 8:733-746.

37. Rao SK, Pavicevic Z, Du Z, Kim JG, Fan M, Jiao Y, Rosebush M, Samant S, Gu W, Pfeffer LM, Nosrat CA. Pro-inflammatory genes as biomarkers and therapeutic targets in oral squamous cell carcinoma. J Biol Chem. 2010; 285:32512-32521.

38. Macha MA, Matta A, Kaur J, Chauhan SS, Thakar A, Shukla NK, Gupta SD, Ralhan R. Prognostic significance of nuclear pSTAT3 in oral cancer. Head Neck. 2011; 33:482-489.

39. Sen M, Thomas SM, Kim S, Yeh JI, Ferris RL, Johnson JT, Duvvuri U, Lee J, Sahu N, Joyce S, Freilino ML, Shi H, Li C, Ly D, Rapireddy S, Etter JP, et al. First-in-human trial of a STAT3 decoy oligonucleotide in head and neck tumors: implications for cancer therapy. Cancer Discov. 2012; 2:694-705.

40. Li N, Grivennikov SI, Karin M. The unholy trinity: inflammation, cytokines, and STAT3 shape the cancer microenvironment. Cancer Cell. 2011; 19:429-431.

41. Mao S, Park Y, Hasegawa Y, Tribble GD, James CE, Handfield M, Stavropoulos MF, Yilmaz O, Lamont RJ. Intrinsic apoptotic pathways of gingival epithelial cells 
modulated by Porphyromonas gingivalis. Cell Microbiol. 2007; 9:1997-2007.

42. Moffatt CE, Lamont RJ. Porphyromonas gingivalis induction of microRNA-203 expression controls suppressor of cytokine signaling 3 in gingival epithelial cells. Infect Immun. 2011; 79:2632-2637.

43. Grivennikov SI, Karin M. Inflammation and oncogenesis: a vicious connection. Curr Opin Genet Dev. 2010; 20:65-71.

44. Kundu SD, Lee C, Billips BK, Habermacher GM, Zhang Q, Liu V, Wong LY, Klumpp DJ, Thumbikat P. The toll-like receptor pathway: a novel mechanism of infection-induced carcinogenesis of prostate epithelial cells. Prostate. 2008; 68:223-229.

45. Rakoff-Nahoum S, Medzhitov R. Toll-like receptors and cancer. Nat Rev Cancer. 2009; 9:57-63.

46. Burns E, Bachrach G, Shapira L, Nussbaum G. Cutting Edge: TLR2 is required for the innate response to Porphyromonas gingivalis: activation leads to bacterial persistence and TLR2 deficiency attenuates induced alveolar bone resorption. J Immunol. 2006; 177:8296-8300.

47. Papadopoulos G, Weinberg EO, Massari P, Gibson FC 3rd, Wetzler LM, Morgan EF, Genco CA. Macrophagespecific TLR2 signaling mediates pathogen-induced TNFdependent inflammatory oral bone loss. J Immunol. 2013; 190:1148-1157.

48. Maekawa T, Krauss JL, Abe T, Jotwani R, Triantafilou M, Triantafilou K, Hashim A, Hoch S, Curtis MA, Nussbaum G, Lambris JD, Hajishengallis G. Porphyromonas gingivalis manipulates complement and TLR signaling to uncouple bacterial clearance from inflammation and promote dysbiosis. Cell Host Microbe. 2014; 15:768-778.

49. Toussi DN, Liu X, Massari P. The FomA porin from Fusobacterium nucleatum is a Toll-like receptor 2 agonist with immune adjuvant activity. Clin Vaccine Immunol. 2012; 19:1093-1101.

50. Kikkert R, Laine ML, Aarden LA, van Winkelhoff AJ. Activation of toll-like receptors 2 and 4 by gram-negative periodontal bacteria. Oral Microbiol Immunol. 2007; 22:145-151.

51. Scheeren FA, Kuo AH, van Weele LJ, Cai S, Glykofridis I, Sikandar SS, Zabala M, Qian D, Lam JS, Johnston D, Volkmer JP, Sahoo D, van de Rijn M, Dirbas FM, Somlo G, Kalisky T, et al. A cell-intrinsic role for TLR2-MYD88 in intestinal and breast epithelia and oncogenesis. Nat Cell Biol. 2014; 16:1238-1248.

52. Chen R, Alvero AB, Silasi DA, Mor G. Inflammation, cancer and chemoresistance: taking advantage of the toll-like receptor signaling pathway. Am J Reprod Immunol. 2007; 57:93-107.
53. Park SR, Kim DJ, Han SH, Kang MJ, Lee JY, Jeong YJ, Lee SJ, Kim TH, Ahn SG, Yoon JH, Park JH. Diverse Toll-like receptors mediate cytokine production by Fusobacterium nucleatum and Aggregatibacter actinomycetemcomitans in macrophages. Infect Immun. 2014; 82:1914-1920.

54. Chung WO, Hansen SR, Rao D, Dale BA. Proteaseactivated receptor signaling increases epithelial antimicrobial peptide expression. J Immunol. 2004; 173:5165-5170.

55. Pahl HL. Activators and target genes of Rel/NF-kappaB transcription factors. Oncogene. 1999; 18:6853-6866.

56. Bond TJ, Young KL, Andrus TT. Characteristics of growth inhibition of Lactobacillus casei by 4-nitroquinoline-noxide. Appl Microbiol. 1970; 20:536-538.

57. Lerner I, Hermano E, Zcharia E, Rodkin D, Bulvik R, Doviner V, Rubinstein AM, Ishai-Michaeli R, Atzmon R, Sherman Y, Meirovitz A, Peretz T, Vlodavsky I, Elkin M. Heparanase powers a chronic inflammatory circuit that promotes colitis-associated tumorigenesis in mice. J Clin Invest. 2011; 121:1709-1721.

58. Han G, Bian L, Li F, Cotrim A, Wang D, Lu J, Deng Y, Bird G, Sowers A, Mitchell JB, Gutkind JS, Zhao R, Raben D, ten Dijke P, Refaeli Y, Zhang Q, et al. Preventive and therapeutic effects of Smad7 on radiation-induced oral mucositis. Nat Med. 2013; 19:421-428.

59. Gioanni J, Fischel JL, Lambert JC, Demard F, Mazeau C, Zanghellini E, Ettore F, Formento P, Chauvel P, Lalanne CM, et al. Two new human tumor cell lines derived from squamous cell carcinomas of the tongue: establishment, characterization and response to cytotoxic treatment. Eur J Cancer Clin Oncol. 1988; 24:1445-1455.

60. Rheinwald JG, Beckett MA. Tumorigenic keratinocyte lines requiring anchorage and fibroblast support cultured from human squamous cell carcinomas. Cancer Res. 1981; 41:1657-1663.

61. Lin CJ, Grandis JR, Carey TE, Gollin SM, Whiteside TL, Koch WM, Ferris RL, Lai SY. Head and neck squamous cell carcinoma cell lines: established models and rationale for selection. Head Neck. 2007; 29:163-188.

62. Zheng LD, Jiang GS, Pu JR, Mei H, Dong JH, Hou XH, Tong QS. Stable knockdown of heparanase expression in gastric cancer cells in vitro. World J Gastroenterol. 2009; 15:5442-5448.

63. de Kok JB, Roelofs RW, Giesendorf BA, Pennings JL, Waas ET, Feuth T, Swinkels DW, Span PN. Normalization of gene expression measurements in tumor tissues: comparison of 13 endogenous control genes. Lab Invest. 2005; 85:154-159. 